\title{
Identifying key domains of health-related quality of life for patients with chronic obstructive pulmonary disease: interviews with healthcare professionals
}

\author{
Muirne C. S. Paap • Christina Bode • \\ Lonneke I. M. Lenferink • Caroline B. Terwee • \\ Job van der Palen
}

Accepted: 6 November 2014/Published online: 16 November 2014 (c) Springer International Publishing Switzerland 2014

\begin{abstract}
Purpose The aim of this paper is to identify which domains of health-related quality of life (HRQoL) are most important for patients with chronic obstructive pulmonary disease (COPD), from the perspective of healthcare professionals (HCPs).

Methods Thirteen Dutch HCPs [six pulmonologists, three pulmonology nurse practitioners, two physiotherapists and two general practitioners; 9 men; mean age 51.0 $(\mathrm{SD}=10.6) \quad$ years; mean years of experience 12.1 $(\mathrm{SD}=7.2)]$ specialized in the field of COPD were recruited. The only inclusion criterion was that the HCP
\end{abstract}

M. C. S. Paap $(\bowtie) \cdot$ J. van der Palen

Department of Research Methodology, Measurement, and Data-Analysis, Behavioral Sciences, University of Twente, P.O. Box 217, 7500 AE Enschede, The Netherlands

e-mail: m.c.s.paap@utwente.nl

C. Bode

Department of Psychology, Health and Technology, Behavioral Sciences, University of Twente, Enschede, The Netherlands

L. I. M. Lenferink

University of Twente, Enschede, The Netherlands

\section{I. M. Lenferink}

Department of Clinical Psychology, Behavioural and Social

Sciences, University of Groningen, Groningen, The Netherlands

\section{B. Terwee}

Department of Epidemiology and Biostatistics, The EMGO Institute for Health and Care Research, VU University Medical Center, Amsterdam, The Netherlands

J. van der Palen

Medical School Twente, Medisch Spectrum Twente, Enschede,

The Netherlands had to have extensive experience in treating COPD patients. The face-to-face interviews took $30-40 \mathrm{~min}$.

Results Physical health emerged as the most important theme from the spontaneous statements that HCPs made when asked about HRQoL in relation to COPD, closely followed by social health and coping with COPD-related complaints and restrictions. The most frequently selected PROMIS domains were fatigue, physical function, emotional support and depression. If the related domains satisfaction with participation in social roles and activities and ability to participate in social roles and activities were to be combined, it would come in second place after fatigue.

Conclusion When comparing the domains chosen by HCPs to the ones chosen by patients in a recent study, there is a high degree of agreement, with the exception of depression. We argue that it is important to take into account both patient and HCP perspective when developing/selecting HRQoL instruments. Our results may be used to inform domain selection to measure $\mathrm{HRQoL}$ in patients with COPD, as well as instrument development.

Keywords COPD - PROMIS - Qualitative research · Physical health $\cdot$ Social health $\cdot$ Mental health

\section{Introduction}

Chronic obstructive pulmonary disease (COPD) is a major cause of chronic morbidity worldwide, and the fourth leading cause of death in the world; the prevalence and mortality are expected to increase even further in the coming decades [1,2]. COPD is characterized by dyspnea, chronic cough, sputum production, a decreased exercise performance and reduced physical activity level [3]. COPD 
cannot be cured; treatments typically focus on reducing the risk factors, managing exacerbations and managing stable COPD [4].

When the goal of treatment is symptom management, it is recommended that the treatment be tailored to the individual patient and the impact of the symptoms on the patient's health-related quality of life (HRQoL) be monitored $[4,5]$. Consequently, there is a growing demand on healthcare professionals (HCPs) to assess and monitor HRQoL and include it in their clinical decision making. This trend has also been documented for other (chronic) diseases, including cancer [6]. In order for treatment to be successful, good patient-HCP interaction is paramount [79]. This is especially true for a treatment setup where HRQoL is one of the main outcome measures. Since HRQoL is highly subjective and typically measured by patient report, it is essential that HCPs elicit this information. HRQoL is a complex construct, thought to consist of many different domains that can be categorized in physical, mental and social health; not all of which may be equally relevant to each patient. This makes it a real challenge for HCPs to come up with the right questions during their consultations in order to assess and monitor HRQoL.

Over the last few decades, over 20 patient reported outcome measures (PROMs) in the form of standardized questionnaires have been developed to facilitate the assessment of HRQoL in COPD patients [10]. Although PROMs hold a lot of promise to help HCPs in assessing HRQoL in a quick and standardized way, picking and choosing from these instruments can be a daunting task. When selecting a questionnaire for a particular application, aspects to consider include domain coverage, test length (e.g., [11, 12]), psychometric properties (e.g., [13]) and whether it is generic or disease specific, among other things [14]. Since both generic and disease-specific instruments have desirable properties, several researchers advocate using both types of instruments to assess HRQoL in patients with COPD [15, 16]; however, HCPs tend to prefer short instruments for use in clinical practice and may therefore not heed these recommendations. Unfortunately, short instruments often fail to provide a sufficiently detailed picture of the most relevant aspects of a patient's HRQoL. In recent years, computerized adaptive testing (CAT) [17] based on item response theory (IRT) [18] has been put forward as a possible solution; it is a digital questionnaire tailored to the individual patient, resulting in each item (question) contributing valuable information, while maintaining comparability across patients. In recent years, a large number of IRT-calibrated item banks covering physical, mental and social health have been developed. This initiative is referred to as Patient-Reported Outcomes Measurement Information System ("PROMIS") [19-21].
Both CATs and short forms have been developed using the item banks. The PROMIS banks are generic and have been calibrated using a large sample from the general population as well as specific patient groups, including COPD. However, no core sets or recommendations are currently available to guide the selection process, nor is it clear whether all domains relevant for COPD are covered by current PROMIS item banks.

Expert panels are widely used in PROM development; the reasons for consulting these experts are typically left unmentioned, however. This is interesting, because many authors have stated that patients are the real experts when it comes to their HRQoL and that if patient and HCP should disagree, the view of the patient should be leading (e.g., [22]). We agree that the patient's view should take center stage, but we also see important reasons for taking the HCP view into account. First, HCPs may be more aware of which domains of HRQoL could benefit from treatment and take this into account when selecting relevant domains. These chances increase if it covers domains that are deemed relevant by HCPs. Finally, HCPs can use their knowledge of COPD patients as a group to complement information put forth by individual patients.

The aim of this paper is to identify which domains of HRQoL are most important for COPD patients, from the HCP patient's perspective. We will do this in two steps: First, HCPs are asked to describe important domains freely; second, they are presented with PROMIS domains and are asked to select those most relevant to them. The HCP is invited to explain the motives behind their choice, providing insight in the way they conceptualize HRQoL.

\section{Methods}

\section{Participants}

Thirteen HCPs in the field of COPD [9 men; mean age 51.0 $(\mathrm{SD}=10.6)$ years; mean years of experience 12.1 $(\mathrm{SD}=7.2)$ ] were recruited throughout the Netherlands. Purposive sampling was used, aimed at maximum obtainable variation with regard to medical profession. Inclusion stopped when saturation was reached. In order to determine the saturation point, we reviewed whether both key HCP characteristics (medical profession) and concepts (main themes/domains) had been adequately sampled [23]. The final group consisted of six pulmonologists, three pulmonology nurse practitioners, two physiotherapists and two general practitioners. Face-to-face interviews (30-40 min) were conducted from July through December 2013. The HCPs all had extensive experience in treating COPD patients. See Table 1 for descriptive characteristics for each HCP. 
Table 1 Healthcare professional characteristics

\begin{tabular}{llllc}
\hline ID & Gender & Age & Profession & $\begin{array}{c}\text { Years of } \\
\text { experience }\end{array}$ \\
\hline 1 & F & 31 & Physiotherapist & 5 \\
2 & M & 37 & Physiotherapist & 10 \\
3 & M & 51 & General practitioner & 15 \\
4 & M & 62 & General practitioner & 14 \\
5 & M & 56 & Pulmonologist & 23 \\
6 & M & 39 & Pulmonologist & 6 \\
7 & F & 40 & Pulmonologist & 3 \\
8 & M & 61 & Pulmonologist & 20 \\
9 & M & 61 & Pulmonologist & 25 \\
10 & M & 60 & Pulmonologist & 13 \\
11 & F & 57 & Pulmonology nurse practitioner & 10 \\
12 & F & 57 & Pulmonology nurse practitioner & 9 \\
13 & M & 51 & Pulmonology nurse practitioner & 4
\end{tabular}

\section{Interview}

The interview was semi-structured (see "Appendix" for the interview scheme). The focus was assessing how COPD impacts HRQoL in patients from the HCPs perspective. The interview scheme consisted of two parts: an open question, and a card sorting task. First, HCPs were asked: "In your opinion, how does COPD affect the patient's quality of life?" Next, HCPs were presented with 16 PROMIS domains (see Fig. 1 for all 16 domain names) printed on separate cards, along with three randomly chosen example items from each domain (see "Appendix"). The HCPs were invited to select and rank the five domains that they deemed most relevant to COPD patient. HCPs were asked to think aloud while making this selection and elaborate on their choices. Each interview was recorded and transcribed verbatim. Official Dutch translations of the PROMIS banks were used [24]. In a previous study, we used a similar procedure to establish which domains were most relevant from the patient's perspective [25].

\section{Ethics}

The study was approved by the ethical review board of the University of Twente. All patients gave informed consent.

Data analysis

The interviews were conducted, audio-recorded and transcribed verbatim by a trained interviewer. HCPs' statements were coded by hand and interpreted by a researcher with ample experience in qualitative research (LL). The coding process was supervised by CB and MP. Coding was performed in several steps. The open question and PROMIS card sorting task were analyzed separately, yet the same coding procedure was used. Prior to coding, irrelevant interview passages (spontaneous statements that do not concern the research question) were removed. We used two types of coding strategies described in grounded theory research: open and axial coding [26]. When using open coding, the data are broken down into units (events, actions, interactions, emotions) that are assigned conceptual labels, so they can be grouped together into themes. When using axial coding, units are related to themes and subthemes. In our study, this process was facilitated by what we refer to as interpretations of meaningful units (see Tables 2, 3 for examples). Additionally, the overall
Fig. 1 Number of times PROMIS domains were selected. Ability to part. in soc. roles and act $=$ ability to participate in social roles and activities; Satisfaction with part. in soc. roles and act. $=$ satisfaction with participation in social roles and activities

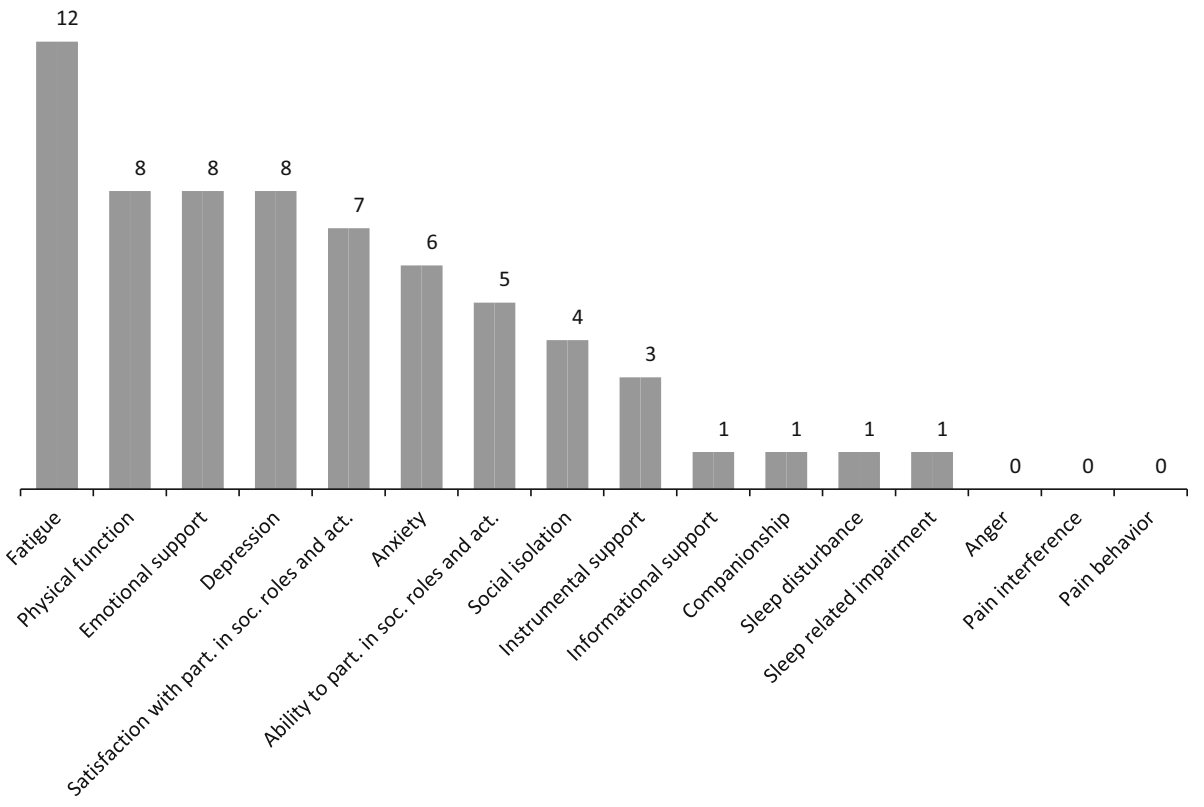


Table 2 Examples showing how units were interpreted and coded into themes for answers given to the open question

\begin{tabular}{|c|c|c|c|}
\hline $\begin{array}{l}\text { Main } \\
\text { theme }\end{array}$ & Sub-theme & Selected unit & Interpretation \\
\hline $\begin{array}{l}\text { Physical } \\
\text { health }\end{array}$ & $\begin{array}{l}\text { No or weak relationship between health- } \\
\text { related quality of life (HRQoL) and the } \\
\text { severity of COPD }\end{array}$ & $\begin{array}{l}\text { "There are people who enter into my office } \\
\text { being very short of breath, who very often } \\
\text { enter suffering from extreme } \\
\text { breathlessness, but they still do all kinds of } \\
\text { activities. They are hardly restricted by it. } \\
\text { Or so it seems. And there are people who } \\
\text { have actually few complaints, and whose } \\
\text { lungs still function fairly well, but who } \\
\text { have all kinds of restrictions" }\end{array}$ & $\begin{array}{l}\text { HRQoL is not related strongly to } \\
\text { severity of COPD }\end{array}$ \\
\hline $\begin{array}{l}\text { Physical } \\
\text { health }\end{array}$ & $\begin{array}{l}\text { Moderate to strong relationship between } \\
\text { HRQoL and severity of COPD }\end{array}$ & $\begin{array}{l}\text { "I think that there's no difference between } \\
\text { healthy and GOLD } 1 \text { [refers to difference } \\
\text { in QoL]. And that there's also relatively } \\
\text { little difference between GOLD } 1 \text { and } \\
\text { GOLD } 2 \text {. There are big steps between } 2 \\
\text { and } 3 \text {, and from } 3 \text { to } 4 \text {. It has to do with the } \\
\text { fact that at that particular moment lung } \\
\text { function is at about } 50 \% \text { of predicted } \\
\text { normal" }\end{array}$ & $\begin{array}{l}\text { In general, lower HRQoL is ascribed } \\
\text { to limited lung capacity }\end{array}$ \\
\hline $\begin{array}{l}\text { Physical } \\
\text { health }\end{array}$ & $\begin{array}{l}\text { Restrictions in physical functioning due to } \\
\text { physical complaints }\end{array}$ & $\begin{array}{l}\text { "People suffering from COPD, especially } \\
\text { people who come to see me; these patients } \\
\text { are very much restricted in their daily } \\
\text { functioning, due to shortness of breath" }\end{array}$ & $\begin{array}{l}\text { Shortness of breath leads to } \\
\text { limitations in daily routine activities }\end{array}$ \\
\hline $\begin{array}{l}\text { Social } \\
\text { health }\end{array}$ & $\begin{array}{l}\text { Not being able to live up to your own } \\
\text { expectations and/or to those of the people } \\
\text { around you leads to a lower HRQoL. Being } \\
\text { able to live up to your own expectations } \\
\text { and/or to those of the people around you } \\
\text { leads to a higher HRQoL. }\end{array}$ & $\begin{array}{l}\text { "That's also a difficult matter, of course. For } \\
\text { when does someone consider their HRQoL } \\
\text { one hundred percent good, that everything } \\
\text { is just fantastic? Person A may use } \\
\text { different criteria than person B. Because it } \\
\text { is a subjective experience. It depends on } \\
\text { certain expectations that you may have, } \\
\text { and these expectations are also influenced } \\
\text { by the people around you" }\end{array}$ & $\begin{array}{l}\text { HRQoL depends on the patients' } \\
\text { expectations and their expectations } \\
\text { are influenced by those of the } \\
\text { people around them }\end{array}$ \\
\hline $\begin{array}{l}\text { Social } \\
\text { health }\end{array}$ & $\begin{array}{l}\text { Physical complaints can cause someone to } \\
\text { feel ashamed }\end{array}$ & $\begin{array}{l}\text { "And a third point is, I think, what women } \\
\text { really hate is coughing up sputum. I once } \\
\text { asked patients to collect sputum for a study } \\
\text { I conducted, and I noticed, much to my } \\
\text { amazement, that women refused point- } \\
\text { blank to participate in a study that involved } \\
\text { coughing up sputum. I'm thinking, well, } \\
\text { it's not that bad, is it? But women are } \\
\text { really ashamed of it. Men are dirty pigs, } \\
\text { they just cough it up. But women really } \\
\text { hate it" }\end{array}$ & $\begin{array}{l}\text { Women are ashamed of coughing up } \\
\text { sputum }\end{array}$ \\
\hline
\end{tabular}

relevance of the domains was expressed by two numbers: An unweighted count of the number of times a domain was chosen, and a weighted sum where the weights were the ranks assigned to each of the chosen domains by the HCPs.

\section{Results}

Open question: "In your opinion, how does COPD affect the patient's quality of life?"

Table 4 presents the seven main themes that emerged from the analysis of the open question, along with sub-themes.
Below, the three main themes that were referred to most frequently (physical health, social health and coping with COPD-related complaints and restrictions) are briefly discussed; for some themes, HCP quotes are given.

All 13 HCPs referred to physical health at least once. Three HCPs believed that there is a moderate to strong relationship between quality of life and severity of COPD (see Table 4); they described that the impact on HRQoL is not very strong for GOLD stages I and II, but that HRQoL deteriorates sharply when passing over into stage III and IV. Seven HCPs were of the opinion that the degree to which COPD influences HRQoL is largely dependent on patient characteristics such as personality, and not 
Table 3 Examples showing how units were interpreted and coded into themes for two PROMIS domains

\begin{tabular}{|c|c|c|c|c|}
\hline $\begin{array}{l}\text { Selected } \\
\text { domain }\end{array}$ & Main theme & Sub-theme & Selected unit & Interpretation \\
\hline Fatigue & $\begin{array}{l}\text { Determinants of } \\
\text { fatigue }\end{array}$ & $\begin{array}{l}\text { Shortness of } \\
\text { breath leads } \\
\text { to fatigue }\end{array}$ & $\begin{array}{l}\text { "Yes, I think that's a very fundamental } \\
\text { feeling, I call them top-level athletes, } \\
\text { COPD patients. You are panting very } \\
\text { heavily, and that means that you are already } \\
\text { using a lot of energy just to breathe. } \\
\text { Normally, } 5 \% \text { of your energy, in this case } \\
\text { it's } 20 \% \text { " }\end{array}$ & $\begin{array}{l}\text { Fatigue is especially connected to shortness } \\
\text { of breath. Breathing requires a great deal } \\
\text { of energy }\end{array}$ \\
\hline Fatigue & $\begin{array}{l}\text { Description of } \\
\text { fatigue }\end{array}$ & $\begin{array}{l}\text { Fatigue is a } \\
\text { common } \\
\text { complaint. }\end{array}$ & $\begin{array}{l}\text { "Yes, actually, all [COPD] patients } \\
\text { experience fatigue. They are short of } \\
\text { breath, but the complaint of fatigue comes } \\
\text { second. They also have difficulty sleeping. } \\
\text { Yes, everything simply demands so much } \\
\text { more energy]" }\end{array}$ & $\begin{array}{l}\text { Fatigue is the second most common } \\
\text { complaint after shortness of breath }\end{array}$ \\
\hline $\begin{array}{l}\text { Physical } \\
\text { function }\end{array}$ & $\begin{array}{l}\text { Experiencing } \\
\text { limitations or } \\
\text { complaints during } \\
\text { physical activities }\end{array}$ & $\begin{array}{l}\text { Limitations } \\
\text { in general } \\
\text { physical } \\
\text { functioning }\end{array}$ & $\begin{array}{l}\text { "It's the first thing people mention. 'I'm } \\
\text { restricted, as it were.' Very clearly and } \\
\text { simply being able to do less. So, when I } \\
\text { ask, 'Gosh, why do you want to rehab?' 'I } \\
\text { simply want to be able to do more; simply } \\
\text { walk, be able to do household chores'” }\end{array}$ & $\begin{array}{l}\text { Being limited in one's physical functioning } \\
\text { is the chief subject of discussion during } \\
\text { consultations }\end{array}$ \\
\hline $\begin{array}{l}\text { Physical } \\
\text { function }\end{array}$ & $\begin{array}{l}\text { Coping with COPD- } \\
\text { related complaints } \\
\text { and limitations }\end{array}$ & $\begin{array}{l}\text { Postponing } \\
\text { physical } \\
\text { activities }\end{array}$ & $\begin{array}{l}\text { "It means that you need to think it through } \\
\text { first, before undertaking anything. And that } \\
\text { you feel you have to constantly postpone } \\
\text { activities, every day, so as to not be } \\
\text { confronted with them [refers to being } \\
\text { confronted with physical limitations] }\end{array}$ & $\begin{array}{l}\text { Before starting a certain activity it should be } \\
\text { considered whether that particular activity } \\
\text { will not cause complaints. That is the } \\
\text { reason why activities are postponed: to } \\
\text { prevent complaints }\end{array}$ \\
\hline
\end{tabular}

primarily on disease severity. Almost half of the HCPs spoke about limitations in physical functioning due to physical complaints, which was often described as restriction in activities of daily living due to physical complaints such as dyspnea. Two HCPs also stated that episodes of exacerbations were highly disabling and some stated that patients often reported physical restrictions, but these two HCPs did not explicitly link physical complaints to limitations in physical functioning. Two HCPs explained inactivity in COPD patients by referring to what they called the "vicious circle of reduced activity."

That people find themselves in a situation where they are unable to lead the lives they want, due to COPD. That means, what poses the biggest problem for them? Limitations in their physical activities, shortness of breath. It means that their radius of action becomes smaller, that they become less active as a result, I think. That they dread physical activities. And, as a consequence, their stamina decreases. Because their stamina decreases, their ability to perform physical activity decreases. That is what is called the 'vicious circle of declining activity.' I watch people gradually turning into a 'rolled-up carpet' in this way. That is, I think, the most important problem. (ID9).

Social health was the second most frequently occurring main theme; the range of subthemes pertaining to this main theme was rather broad (see Table 4). The extent to which patients were able to meet expectations was mentioned most often, together with being part of the active workforce (see Table 4). One HCP found that continuing to work negatively affects patients' social lives, due to increased risk of burnout-related complaints, while another $\mathrm{HCP}$ stated that leaving or losing a job causes patients to lose a significant part of their social network. The common denominator in all subthemes was that COPD patients seem to have difficulty dealing with the effect their physical decline has on their social life. HCPs stated that patients reported that they feel ashamed of their physical complaints, such as coughing and sputum (see Table 2); that they no longer have a real social life because they avoid going out and therefore feel they are no longer a part of society; and that they experience negative responses from others, such as lack of understanding.

Coping with COPD was the third most frequently occurring main theme; HCPs reported that patients differ in their way of coping with COPD. The most frequently heard statements associated with the main theme of coping, revolved around adequate adaption to COPD and personality characteristics. Some HCPs stated that adequate adaptation to COPD is key to coping with COPD. Examples of adequate adaptation were adjustment of physical activity to physical decline, acceptance of physical decline and adjustment of standards and expectations. In the 
Table 4 Overview of themes and subthemes associated with the open question

\begin{tabular}{|c|c|c|}
\hline $\begin{array}{l}\text { Main themes (number of } \\
\text { occurrences) }\end{array}$ & $\begin{array}{l}\mathrm{N} \text { (number of } \mathrm{HCPs} \\
\text { referring to main theme) }\end{array}$ & Subthemes (number of occurrences) \\
\hline Physical health (22) & 13 & $\begin{array}{l}\text { No or weak relationship between health-related quality of life (HRQoL) and } \\
\text { severity of COPD (7) } \\
\text { Limitation in physical functioning due to physical complaints (6) } \\
\text { Moderate to strong relationship between HRQoL and severity of COPD (3) } \\
\text { Episodes of exacerbation are perceived as very detrimental (2) } \\
\text { Limitation in physical functioning (2) } \\
\text { Vicious circle of reduced activity: decreased lung capacity leads to limitation in } \\
\text { activity, which leads to a decline in stamina, which in turn leads to further } \\
\text { decrease in physical activity (2) }\end{array}$ \\
\hline Social health (15) & 9 & $\begin{array}{l}\text { Not being able to meet your own expectations and/or those of the people around } \\
\text { you leads to lower HRQLL/Being able to meet your own expectations and/or } \\
\text { those of the people around you leads to higher HRQoL (3) } \\
\text { Employment affects HRQoL (3) } \\
\text { Physical complaints can lead to shame (2) } \\
\text { Limitation in physical functioning leads to loss of social contact (2) } \\
\text { Lack of understanding from social surrounding (2) } \\
\text { Psychosocial well-being influences HRQoL (1) } \\
\text { Social life is a very important aspect of HRQoL (2) } \\
\text { Not being able to fulfill traditional gender roles anymore (1) }\end{array}$ \\
\hline $\begin{array}{l}\text { Coping with COPD-related } \\
\text { complaints and restrictions (13) }\end{array}$ & 6 & $\begin{array}{l}\text { Adequate ability to adapt leads to higher HRQoL/inadequate ability to adapt } \\
\text { leads to lower HRQoL (5) } \\
\text { Personality characteristics influence the way complaints and limitations are } \\
\text { handled (5) } \\
\text { Accepting COPD leads to improved HRQoL (1) } \\
\text { Downward comparison leads to putting complaints into perspective (1) } \\
\text { Cultural background is a determinant of coping behavior (1) }\end{array}$ \\
\hline $\begin{array}{l}\text { Additional factors that effect } \\
\text { QoL (2) }\end{array}$ & 2 & $\begin{array}{l}\text { Comorbidity has a negative effect on HRQoL (1) } \\
\text { Meaningfulness or purpose in life has a positive influence on HRQoL (1) }\end{array}$ \\
\hline Knowledge (2) & 2 & $\begin{array}{l}\text { Lack of knowledge leads to lower QoL/Increase of knowledge leads to higher } \\
\text { HRQoL (2) }\end{array}$ \\
\hline Anxiety (1) & 1 & Fear of physical activity (1) \\
\hline Anger (1) & 1 & Frustration level determines how disease burden is perceived (1) \\
\hline
\end{tabular}

majority of statements pertaining to coping, HCPs stress that the ability of COPD patients to cope with their disease depends largely on their personality; some patients more readily accept that they have COPD than others; some patients assume a victim role, while others stay very active; some patients are better at putting things in perspective; and also cultural factors were mentioned.

Int: How is that? [Refers to QoL being dependent on the patient's personality]?

ID6: I think it has a lot to do with the patient's personality traits. There are people who just step up and deal with problems more readily than others. And there are fighters who persevere, sometimes against all odds. Who just won't quit. So, I think that the patient's inner drive is very important. (ID6)
Selecting the most relevant PROMIS domains

The card sorting method produced results on the relative importance of the PROMIS domains (Fig. 1). The statements that the HCPs gave when motivating their choice of domains were coded into main themes and subthemes, similar to the analysis of the open question. In Table 5, all main themes are listed per PROMIS domain. The five most popular PROMIS domains are described in more detail below.

Fatigue was the most frequently chosen domain, followed by physical functioning, emotional support, depression and satisfaction with participation in social roles and activities (Fig. 1). Weighting the times a domain was chosen using the rank order did not change the results: The same five PROMIS domains emerged in the top five 
Table 5 Overview of main themes derived from healthcare professionals' statements associated with the selected PROMIS domain

\begin{tabular}{|c|c|c|}
\hline Selected theme & Main themes & $\begin{array}{l}\text { Number of } \\
\text { occurrences }\end{array}$ \\
\hline \multirow[t]{4}{*}{ Fatigue } & Determinants of fatigue & 15 \\
\hline & Description of fatigue & 13 \\
\hline & Effects of fatigue & 2 \\
\hline & Coping with fatigue & 2 \\
\hline \multirow[t]{5}{*}{ Physical function } & Experiencing limitations or complaints during physical activities & 8 \\
\hline & Autonomy & 3 \\
\hline & Coping with COPD-related complaints and limitations & 3 \\
\hline & Anger & 1 \\
\hline & Depression & 1 \\
\hline \multirow[t]{2}{*}{ Emotional support } & Description of emotional support & 7 \\
\hline & Effects of social support & 4 \\
\hline \multirow[t]{4}{*}{ Depression } & Determinants of depression & 5 \\
\hline & Diagnosis of depression & 4 \\
\hline & Description of depression & 3 \\
\hline & Coping with depression & 1 \\
\hline \multirow[t]{5}{*}{$\begin{array}{l}\text { Satisfaction with participation in social roles and } \\
\text { activities }\end{array}$} & $\begin{array}{l}\text { Determinants of limitation in participation in social roles and } \\
\text { activities }\end{array}$ & 4 \\
\hline & Effects of participation in social roles and activities & 3 \\
\hline & Description of participation in social roles and activities & 3 \\
\hline & Role functioning & 2 \\
\hline & Self-reliance & 1 \\
\hline \multirow[t]{5}{*}{ Anxiety } & Description of anxiety & 20 \\
\hline & Effects of anxiety & 3 \\
\hline & Diagnosis of anxiety & 2 \\
\hline & Treatment of anxiety & 1 \\
\hline & Determinants of anxiety & 1 \\
\hline \multirow[t]{5}{*}{ Ability to participate in social roles and activities } & $\begin{array}{l}\text { Determinants of limitation in participation in social roles and } \\
\text { activities }\end{array}$ & 5 \\
\hline & Emotional health & 3 \\
\hline & $\begin{array}{l}\text { Description of importance of participation in social roles and } \\
\text { activities }\end{array}$ & 2 \\
\hline & Effects of participation in social roles and activities & 1 \\
\hline & Coping with COPD-related complaints and limitations & 1 \\
\hline \multirow[t]{4}{*}{ Social isolation } & Determinants of social isolation & 5 \\
\hline & Effects of social isolation & 1 \\
\hline & Role functioning & 1 \\
\hline & Social environment & 1 \\
\hline \multirow[t]{2}{*}{ Instrumental support } & Impediments to obtaining instrumental support & 4 \\
\hline & Description of instrumental support & 3 \\
\hline \multirow[t]{2}{*}{ Informational support } & Effects of increase of knowledge about COPD & 1 \\
\hline & Effects of lack of knowledge about COPD & 1 \\
\hline Companionship & Effects of companionship & 1 \\
\hline \multirow[t]{2}{*}{ Sleep disturbance } & Determinants of sleep disturbance & 1 \\
\hline & Effects of sleep disturbance & 1 \\
\hline Sleep-related impairment & Determinants of sleep-related impairment & 1 \\
\hline
\end{tabular}


most frequently chosen domains, but in a different order (data not shown).

Almost all HCPs selected fatigue, their main reason being that it is frequently reported by patients. Some HCPs stated fatigue is the second most common complaint, after dyspnea (see Table 3). When explaining their choice for this domain, the majority of HCPs elaborated on the determinants of fatigue, or gave a description of the way fatigue manifests itself in patients with COPD, or did both. Some HCPs argued that factors such as shortness of breath, having a job and tobacco use may play an important role in causing fatigue (see Table 3 ).

Eight HCPs selected the domain physical function; their main reason being the substantial impact it has on patients' lives when they experience a decline in physical function due to their COPD (see Table 3). For example, HCPs mentioned that patients may experience difficulties in performing activities of daily living; in some cases, patients postpone or altogether avoid performing certain activities (see Table 3). Several HCPs reported that this decline in physical function is difficult to accept or adjust to for a majority of patients, which leads to feelings of anger, depression and loss of autonomy.

Physical functioning has, opens the door to independence for many people. And if it's restricted, severely restricted, [...] then people become dependent on others, as a result of which their quality of life decreases. (ID4)

Eight HCPs selected the domain emotional support, explaining this choice by focusing on the kind of emotional support patients did or did not receive, the effects of receiving or not receiving this support or both. There were two opposite angles: negative or positive. The majority focused on the negative and stated that patients receive little to no emotional support or that the people around them have little or no understanding of their COPD. HCPs often hear that patients feel left out, misunderstood and neglected. The consequences of a lack of emotional support are social isolation and feelings of loneliness. HCPs who focused on the positive reported that receiving emotional support is very important to patients and could lead, for example, to development of adequate coping skills and eventually improvement in physical functioning.

Eight HCPs selected the domain depression; the main reason being that issues associated with COPD often lead to feelings of depression in patients. HCPs described depression as feelings of sadness and apathy and not feeling comfortable in your own skin. Physical decline, anxiety, social isolation or staying at home in autumn and winter were mentioned as examples of determinants. Other frequently reported comments revolved around recognizing or diagnosing depression. HCPs stated that although many patients suffer from depression, it is not easy to detect due to lack of awareness among doctors and patients alike; establishing the correct diagnosis may be hampered if patients are in denial about their depression.

But in my office, if I suspect it, I will refer them to a specialist, yes. And I think that especially depression in older COPD-patients often goes undetected, although it's very common. Pulmonologists don't always realize that, although it's of great importance in connection with quality of life. (ID6)

Seven HCPs selected the domain satisfaction with participation in social roles and activities; they pointed out that there is an important causal pathway involving physical function, social roles and activities and emotions. It should be noted that HCPs found it difficult to distinguish between satisfaction with participation in social roles and activities and ability to participate in social roles and activities. Only one HCP chose both of these domains. The statements the HCP gave, when selecting one of these domains, did not differ between the two domains. If we would look at the preference shown for these two domains combined, it would have come in second place, after fatigue $(n=11)$. HCPs reported that good physical function is a necessary condition for participation in social roles and activities. Due to physical restrictions, patients often have to give up their hobbies, leading to negative emotions such as sadness and grief. If patients do participate socially, despite their physical restrictions, this is reported to have positive results, such as improved selfesteem and positive mood.

But, for instance, one of my patients likes playing pool. But he does it somewhere where people smoke a lot and he can't stand it. To his great regret, he had to leave his billiards club. He used to go there every afternoon. People who like to go fishing, who can't sit outside anymore because of the cold. For they can't bear the cold, because it causes shortness of breath. Or they can't carry the heavy gear to the waterside. It's small things. People who can't dance anymore in their leisure time, because they start to cough and rasp. (ID11)

\section{Discussion}

The aim of this paper was to identify which domains of HRQoL are most important for COPD patients, from the HCP patient's perspective. Physical health emerged as the most important domain from the spontaneous statements that HCPs made, closely followed by social health and coping with COPD-related complaints and restrictions. The 
most frequently selected PROMIS domains were fatigue, physical function, emotional support and depression. If the related domains satisfaction with participation in social roles and activities and ability to participate in social roles and activities were to be combined, it would come in second place after fatigue.

In a recent study [25], we proposed a framework outlining a series of steps that could be taken to develop a multidimensional CAT to measure HRQoL in patients with COPD. The first step entails targeting relevant domains and subdomains, using interviews with patients and HCPs, literature and existing HRQoL models as input. Our approach shows some methodological similarities to the approach used by Victorson et al. [27] in developing a conceptual model of the experience of dyspnea in COPD. Like Victorson et al., we emphasize the importance of combining theoretical knowledge with patient perspective and expert opinion. The differences lie in how we elicit this expert opinion and how it is used. Victorson et al. invited experts to provide assistance with the coding procedure and to "review concepts for their relevance and fit to the clinical setting of COPD." We, on the other hand, conducted two highly similar rounds of interviews with both patients and HCPs in parallel, since we wanted to be able to pinpoint exactly for which domains the agreement and differences in opinion occur.

We recently showed that the most relevant (sub) domains of HRQoL for patients with COPD were as follows: physical health (PROMIS domains fatigue, physical function), social health (PROMIS domains instrumental support, ability to participate in social roles and activities, companionship and emotional support) and coping with COPD (open question) [24]. When comparing these outcomes to the ones in this study, there is a high degree of overlap. This is a somewhat surprising result, since other researchers that included both patient and HCP perspective in their research pertaining to chronic diseases have reported marked discrepancies in the two perspectives [2830]. There was one clear exception to this high agreement between patients and HCPs: depression. It was expected that both patients and HCPs would select depression, since the prevalence of depression or the level of depressive symptoms is reported to be much higher in patients with COPD than in the general population [31-34]. Although more than half of the HCPs chose this domain, none of the patients did. HCPs did indicate that it is hard for patients to talk about depression. It should be noted that although depression was not explicitly chosen, depressive feelings were mentioned by some patients in relation to other domains or themes, such as fatigue, autonomy and acute exacerbations. We speculated that patients may have felt a bit daunted when confronted with the word depression directly. We therefore encourage clinicians and researchers to continue asking about and investigating depressive symptoms in COPD. Another interesting contrast emerged with respect to Instrumental Support: Only three HCPs chose this domain, where approximately half of the interviewed patients did. This indicates that a lot of HCPs may possibly overlook an important aspect of HRQoL for COPD patients. Interestingly, the three HCPs that did select Instrumental Support all had a different medical profession; thus, we cannot simply attribute this finding to HCPs with specific professions not paying attention to this aspect of HRQoL. Based on our results, we encourage clinicians and researchers to include instrumental support in their assessment of COPD patients.

While patients predominantly described domains related to social health in positive terms (important relationships they had, and help that they received), HCPs focused more on the negative aspects (what patients had to do without, how little their social environment understood of their illness, how alone the patients felt). In a study about definitions of QoL in cardiac out-patients, Woodend et al. [30] also found that patients chose to focus on positive aspects of life when compared to HCPs. They concluded that quality of life measures "...developed from the perspective of primary caregivers are probably invalid and (...) should therefore be developed from a patient perspective." We prefer a different approach. We view the two angles (patients and HCPs) as being complementary. Focusing mostly on the positive things may be a functional coping mechanism for patients. When they speak to a HCP, patients may be more inclined to report problems. As a result, HCPs may not get the full story and thus have a onesided picture. On the other hand, when talking to an interviewer, patients may be more inclined to provide socially desirable answers.

Almost half of the HCPs indicated that they felt it was almost impossible to choose domains of HRQoL that were relevant to all COPD patients, irrespective of their disease severity (GOLD stage). They would have preferred to choose one set of domains for GOLD I/II (mild-moderate severity), and another set for GOLD III/IV (severe-very severe). Since so many HCPs indicated that this may be of importance, we looked at group differences in the patient data (data not shown). We found that GOLD III/IV patients focused more on psychological and social effects of their COPD-related impairment, whereas GOLD I/II patients focused more on physical functioning and symptoms. It may be that patients in an early stage of COPD have yet to come to terms with the symptoms they are experiencing. Patients in later stages may have found ways to adapt their lives to the illness, which is accompanied by a sense of loss and impairment when they compare their current lives to what they used to be. The difference between these two subgroups was large enough to warrant further research. 
Several HCPs indicated that it was sometimes difficult to choose among PROMIS domains since some were very similar, especially the sleep-related domains; social isolation versus emotional support; and satisfaction with participation in social roles and activities and ability to participate in social roles and activities. This slightly obfuscates our frequency findings (Fig. 1), where the two domains now come in fifth and seventh place, respectively. Were they to be combined, they would be in second place. Four HCPs indicated that they were not satisfied with the coverage of the concept of HRQoL (with respect to COPD) by the 16 PROMIS domains. They missed certain domains, including dyspnea, embarrassment, purpose in life, sexuality and palliative care.

\section{Conclusion}

Combining patient and $\mathrm{HCP}$ perspective, we propose the following set of PROMIS domains for assessing HRQoL in COPD:

\section{- Fatigue}

- Physical function

- Satisfaction with/ability to participate in social roles and activities

- Companionship

- Emotional support

- Instrumental support

- Depression

The results of our research may be used to select PROMIS domains to measure HRQoL in patients with COPD, as well as to inform instrument development. We are currently developing a computerized adaptive test to measure HRQoL in patients with COPD [25]. We will combine three of the above-mentioned PROMIS domains with a disease-specific module that covers other important topics that emerged in the interviews with patients and HCPs, including coping with COPD, dyspnea and autonomy. Combining PROMIS domains with a COPD-specific module will facilitate comparisons with other disease groups and the general population while at the same timing eliciting important COPD-attributed information (see [35]). If one would like to use PROMIS domains only, domains such as Psychological Impact of Illness (Positive and Negative), Dyspnea Severity and Dyspnea Functional Limitations may be viable alternatives.

Acknowledgments We thank Mitzi Paap, Bachelor of Arts in English language and culture, for translating the interview scheme, tables and quotes from Dutch to English. We also thank all healthcare professionals that participated in this study and Jurrie Eijhuisen for conducting the interviews. This study was supported by Grant \#3.4.11.004 from Lung Foundation Netherlands.

\section{Appendix: Script and interview schedule "Interviews with health professionals about quality of life in COPD patients"}

Written by Muirne Paap, Christina Bode \& Jurrie Eijhuisen, University of Twente

Translated to English by Mitzi Paap

Interviews with health professionals about quality of life in COPD patients

Name interviewer: Jurrie Eijhuisen

Name health professional:

Function health professional:

Date:

Time:

Place:

\section{Introduction}

Introducing myself

My name is Jurrie Eijhuisen. I am a private practice physiotherapist. While working as a physiotherapist I study psychology. After completing my bachelor's degree, I entered a master's degree in health psychology at the University of Twente, in Enschede. Currently, I am writing my master's thesis on quality of life in COPD patients from the health professional's point of view.

Subject

There are all kinds of different questionnaires in existence to assess quality of life in patients with chronic diseases. All these questions can be subdivided into different domains. My research aims to assess, by means of interviews, which of these domains are the most relevant in connection to COPD, according to health professionals. This research study contributes to the development of a computer adaptive test (CAT) which may replace existing paper-and-pencil tests.

Processing data

The interviews will be analyzed and recorded in a report, ensuring anonymity and confidentiality. Possibly, the report will be published as well. 
Confidentiality

The research results will be used for scientific purposes only. Your personal information will not be identifiable.

Duration

The interview will take 20-30 minutes

Audio recording

During the interview I will take notes. In addition, I would like to audio record the interview, as it will improve the accuracy of my report. Please, be assured that the audio recordings will be deleted when the research has been completed.

Do you object to the use of an audio recorder during the interview? YES/NO

Any questions or remarks at this stage?
General questions

I would like to begin with a few general questions (possibly the questions have already been answered through email):

- What is your profession?

- Have you got a specialization? YES/NO. If YES, what is your specialization?

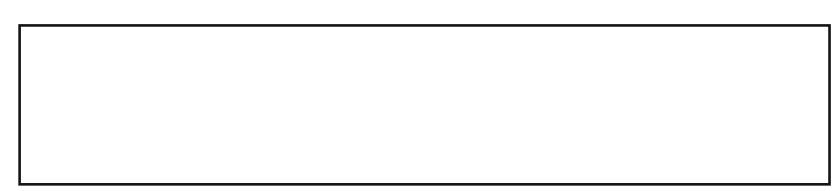

Before we start, I would like to ask you to carefully read this consent form. I want to be certain that you are well informed of the research study. I want to stress that it is not a contract, and that you may withdraw from the study at any time, without giving reasons. By signing this form, you indicate that you have read the aforementioned information and that you agree to the conditions.

\section{-Present consent form-}

Central focus

We shall now start the interview. Remember that there are no right or wrong answers. It is about your personal experience and your personal opinion.
- How long have you been at your current position?

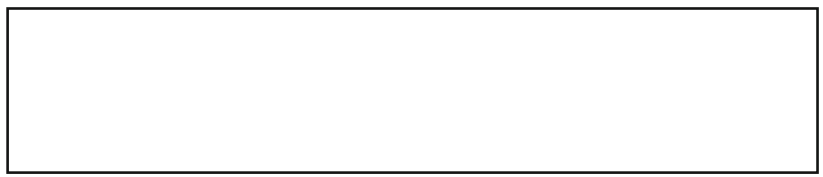

Domains

Now I will pose a few questions regarding different domains of quality of life in COPD patients:

- In your opinion, how does COPD affect the patient's quality of life?
-Start audio recording
- Can you indicate what the reasons could be? 
I will put down sixteen cards in front of you. On these cards, sixteen domains of quality of life are described, each accompanied by a few examples. I would like you to choose five domains of quality of life which, in your view, are the most affected in COPD patients. Try to focus on the general contents of each domain

-let the respondent select five cards-

You indicate that the following five domains are the most affected by COPD:

-read the texts on the five cards aloud-

Carefully study these cards again. Arrange the cards from least important to most important. -let the respondent arrange the five cards-

The way you have arranged the cards indicates that you consider the following domains as the most relevant in connection with COPD:

1.

2.

3.

4.

5.

-Per domain-:

Can you indicate why this domain is important in connection with COPD? 


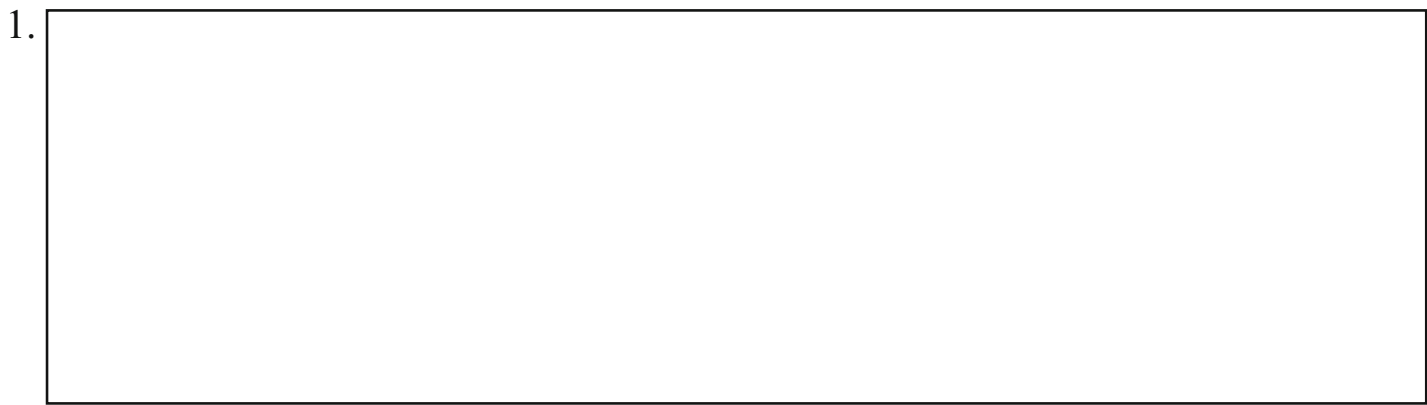

2.

3.

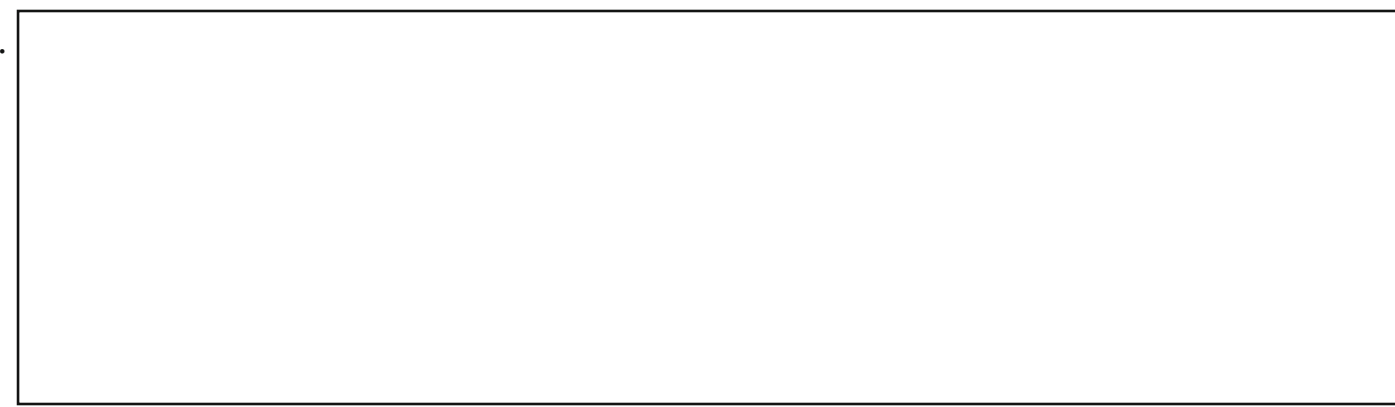

4.

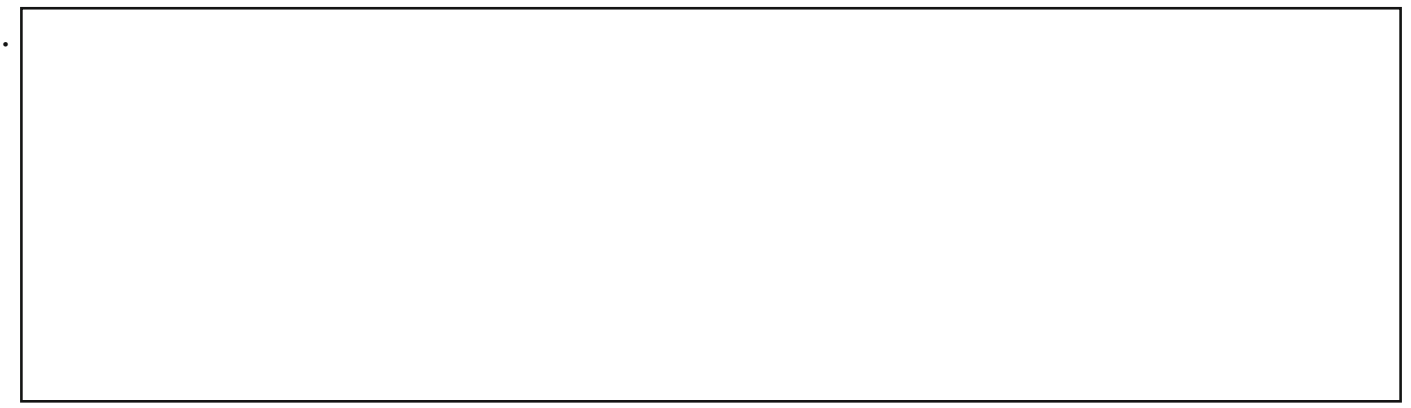

5. 
-When you are using instruments to measure quality of life in COPD patients, do you have a preference for 1 overall score or for specific domain scores?

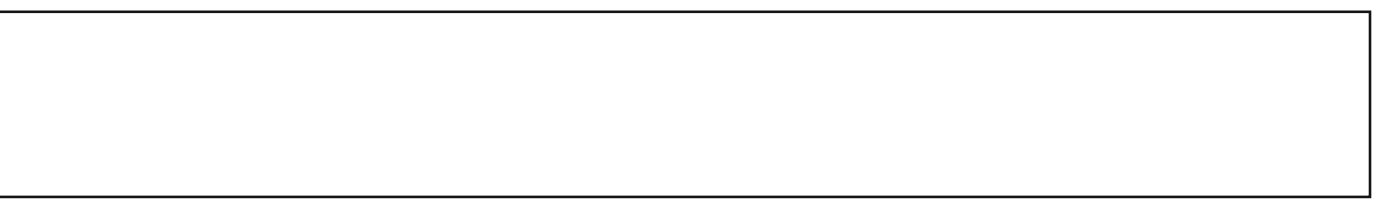

-Can you indicate why you prefer 1 overall score / specific domain scores?

In a previous research study, the same questions were put to COPD patients. They did not all give the same answers. However, the study showed clear preferences in COPD patients.

The four domains the most frequently selected by COPD patients were:

-show cards with the domains concerned-

'ability to participate in social roles and activities'

'instrumental support'

'fatigue'

'physical functioning'

- How does this outcome strike you?
COPD patients, what are the most significant similarities and differences?

- You have listed five domains of quality of life which, in your view, are the most affected in COPD patients. If you compare your list with the list of preferences in 
- Can you elaborate on these similarities and/or differences?

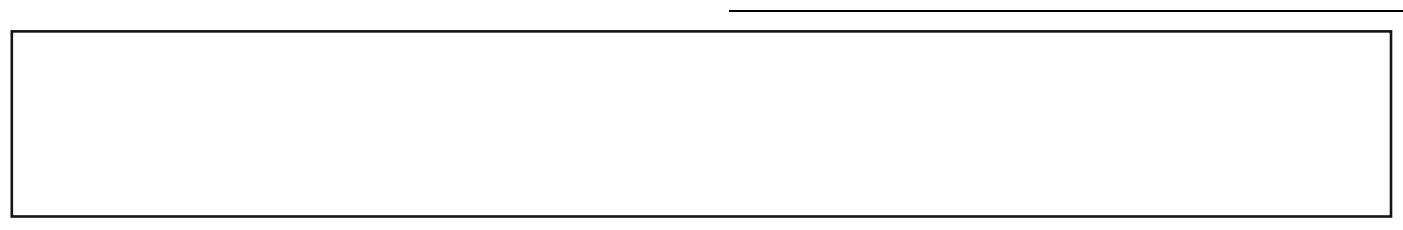

\section{Conclusion}

- Is there anything else you would like to add?

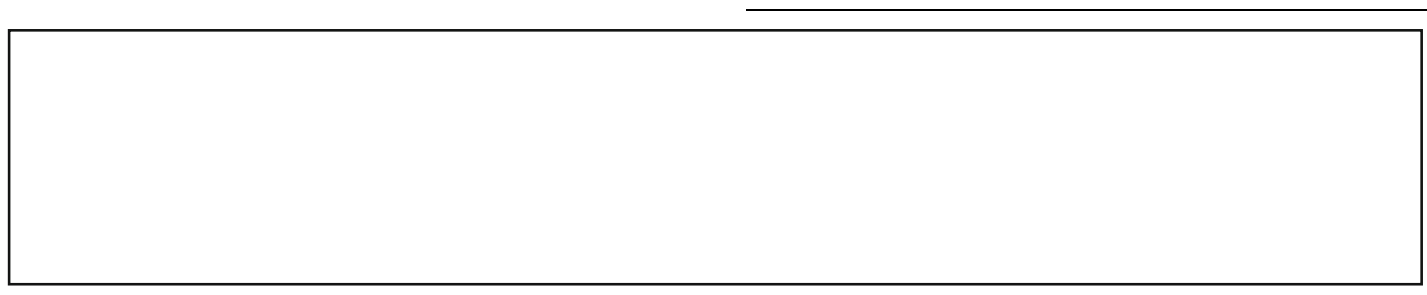

- This is the end of the interview. Have you got any questions or remarks?

- How do you feel about this interview? 


\section{-stop audio recording-}

\section{References}

1. Lopez, A. D., Shibuya, K., Rao, C., Mathers, C. D., Hansell, A. L., Held, L. S., et al. (2006). Chronic obstructive pulmonary disease: Current burden and future projections. European Respiratory Journal, 27(2), 397-412. doi:10.1183/09031936.06. 00025805

2. WHO (2013). Chronic obstructive pulmonary disease (COPD) (Fact Sheet No. 315). http://www.who.int/mediacentre/factsheets/ fs315/en/. Accessed 13 May 2014.

3. Nici, L., Donner, C., Wouters, E., Zuwallack, R., Ambrosino, N., Bourbeau, J., et al. (2006). American thoracic society/European respiratory society statement on pulmonary rehabilitation. American Journal of Respiratory and Critical Care Medicine, 173(12), 1390-1413. doi:10.1164/rccm.200508-1211ST.

4. Global Initiative for Chronic Obstructive Lung Disease. (2007). Global strategy for the diagnosis, management, and prevention of chronic obstructive pulmonary disease. http://www.goldcopd. org/Guidelines/guidelines-global-strategy-for-diagnosis-manage ment-2007.html.

5. Pauwels, R. A., Buist, A. S., Calverley, P. M., Jenkins, C. R., \& Hurd, S. S. (2001). Global strategy for the diagnosis, management, and prevention of chronic obstructive pulmonary disease. NHLBI/WHO global initiative for chronic obstructive lung disease (GOLD) Workshop summary. American Journal of Respiratory and Critical Care Medicine, 163(5), 1256-1276. doi:10. 1164/ajrccm.163.5.2101039.

6. Velikova, G., Awad, N., Coles-Gale, R., Wright, E. P., Brown, J. M., \& Selby, P. J. (2008). The clinical value of quality of life assessment in oncology practice - a qualitative study of patient and physician views. Psycho-Oncology, 17(7), 690-698. doi:10. 1002/pon.1295.

7. Oosterhof, B., Dekker, J. H., Sloots, M., Bartels, E. A., \& Dekker, J. (2014). Success or failure of chronic pain rehabilitation: The importance of good interaction-a qualitative study under patients and professionals. Disability and Rehabilitation,. doi:10. 3109/09638288.2014.881566.

8. DiMatteo, M. R. (1998). The role of the physician in the emerging health care environment. Western Journal of Medicine, 168(5), 328-333.

9. Ha, J. F., \& Longnecker, N. (2010). Doctor-patient communication: A review. Ochsner Journal, 10(1), 38-43.

10. Weldam, S. W., Schuurmans, M. J., Liu, R., \& Lammers, J. W. (2012). Evaluation of quality of life instruments for use in COPD care and research: A systematic review. International Journal of Nursing Studies, doi:10.1016/j.ijnurstu.2012.07.017.

11. Kruyen, P. M., Emons, W. H. M., \& Sijtsma, K. (2013). On the shortcomings of shortened tests: A literature review. International Journal of Testing, 13(3), 223-248. doi:10.1080/15305058. 2012.703734 .

12. Kruyen, P. M., Emons, W. H. M., \& Sijtsma, K. (2013). Assessing individual change using short tests and questionnaires. Applied Psychological Measurement,. doi:10.1177/ 0146621613510061.

13. Paap, M. C. S., Brouwer, D., Glas, C. A. W., Monninkhof, E. M., Forstreuter, B., Pieterse, M. E., et al. (2013). The St George's respiratory questionnaire revisited: A psychometric evaluation. Quality of Life Research, doi:10.1007/s11136-013-0570-y.

14. Barclay-Goddard, R., Epstein, J. D., \& Mayo, N. E. (2009). Response shift: A brief overview and proposed research priorities. Quality of Life Research, 18(3), 335-346. doi:10.1007/ s11136-009-9450-x.

15. Ackerman, T. A. (1996). Developments in multidimensional item response theory. Applied Psychological Measurement, 20, 309-310.

16. Daudey, L., Peters, J. B., Molema, J., Dekhuijzen, P. N., Prins, J. B., Heijdra, Y. F., et al. (2010). Health status in COPD cannot be measured by the St George's respiratory questionnaire alone: An evaluation of the underlying concepts of this questionnaire. Respiratory Research, 11, 98. doi:10.1186/1465-9921-11-98.

17. Van der Linden, W. J., \& Glas, C. A. W. (Eds.). (2000). Computerized adaptive testing: Theory and practice. Dordrecht: Kluwer.

18. Embretson, S. E., \& Reise, S. (2000). Item response theory for psychologists. Mahwah, NJ: Erlbaum.

19. Cella, D., Yount, S., Rothrock, N., Gershon, R., Cook, K., Reeve, B., et al. (2007). The Patient-Reported Outcomes Measurement Information System (PROMIS): Progress of an NIH Roadmap cooperative group during its first two years. Medical Care, $45(5$ Suppl 1), S3-S11. doi:10.1097/01.mlr.0000258615.42478.55.

20. PROMIS (2014). Domain frameworks PROMIS adult selfreported health. http://www.nihpromis.org/measures/domain framework1. Accessed 25 Feb 2014.

21. Cella, D., Riley, W., Stone, A., Rothrock, N., Reeve, B., Yount, S., et al. (2010). The Patient-Reported Outcomes Measurement Information System (PROMIS) developed and tested its first wave of adult self-reported health outcome item banks: 2005-2008. Journal of Clinical Epidemiology, 63(11), 1179-1194. doi:10.1016/j.jclinepi.2010.04.011.

22. Fitzsimmons, D., George, S., Payne, S., \& Johnson, C. D. (1999). Differences in perception of quality of life issues between health professionals and patients with pancreatic cancer. Psychooncology, 8(2), 135-143.

23. Brod, M., Tesler, L., \& Christensen, T. (2009). Qualitative research and content validity: Developing best practices based on science and experience. Quality of Life Research, 18, 1263-1278.

24. Terwee, C. B., Roorda, L. D., Vet, H. C. W., Dekker, J., Westhovens, R., Leeuwen, J., et al. (2014). Dutch-Flemish translation of 17 item banks from the Patient-Reported Outcomes Measurement Information System (PROMIS). Quality of Life Research, 1-9, doi:10.1007/s11136-013-0611-6.

25. Paap, M. C. S., Bode, C., Lenferink, L. I. M., Groen, L. C., Terwee, C. B., Ahmed, S., et al. (2014). Identifying key domains of health-related quality of life for patients with chronic obstructive pulmonary disease: The patient perspective. Health and Quality of Life Outcomes, 12, 106. doi:10.1186/s12955-0140106-3.

26. Corbin, J., \& Strauss, A. (1990). Grounded theory research: Procedures, canons, and evaluative criteria. Qualitative Sociology, 13(1), 3-21. doi:10.1007/bf00988593.

27. Victorson, D. E., Anton, S., Hamilton, A., Yount, S., \& Cella, D. (2009). A conceptual model of the experience of dyspnea and functional limitations in chronic obstructive pulmonary disease. Value Health, 12(6), 1018-1025. doi:10.1111/j.1524-4733.2009. 00547.x.

28. Bartlett, S. J., Hewlett, S., Bingham, C. O, 3rd, Woodworth, T. G., Alten, R., Pohl, C., et al. (2012). Identifying core domains to assess flare in rheumatoid arthritis: An OMERACT international patient and provider combined Delphi consensus. Annals of the Rheumatic Diseases, 71(11), 1855-1860. doi:10.1136/annrheum dis-2011-201201.

29. Clark, M., \& Hampson, S. E. (2003). Comparison of patients' and healthcare professionals' beliefs about and attitudes towards Type 2 diabetes. Diabetic Medicine, 20(2), 152-154. doi:10.1046/j. 1464-5491.2003.00896.x. 
30. Woodend, A. K., Nair, R. C., \& Tang, A. S. (1997). Definition of life quality from a patient versus health care professional perspective. International Journal of Rehabilitation Research, 20(1), 71-80.

31. von Leupoldt, A., \& Kenn, K. (2013). The psychology of chronic obstructive pulmonary disease. Current Opinion in Psychiatry, 26(5), 458-463. doi:10.1097/YCO.0b013e328363c1fc.

32. Di Marco, F., Verga, M., Reggente, M., Maria Casanova, F., Santus, P., Blasi, F., et al. (2006). Anxiety and depression in COPD patients: The roles of gender and disease severity. Respiratory Medicine, 100(10), 1767-1774. doi:10.1016/j.rmed. 2006.01.026.

33. Maurer, J., Rebbapragada, V., Borson, S., Goldstein, R., Kunik, M. E., Yohannes, A. M., et al. (2008). Anxiety and depression in
COPD: Current understanding, unanswered questions, and research needs. Chest, 134(4 Suppl), 43s-56s. doi:10.1378/chest. 08-0342.

34. Zhang, M. W., Ho, R. C., Cheung, M. W., Fu, E., \& Mak, A. (2011). Prevalence of depressive symptoms in patients with chronic obstructive pulmonary disease: A systematic review, meta-analysis and meta-regression. General Hospital Psychiatry, 33(3), 217-223. doi:10.1016/j.genhosppsych.2011.03.009.

35. Cook, K., Kallen, M., Cella, D., Crane, P., Eldadah, B., Hays, R., et al. (2014). The Patient Reported Outcomes Measurement Information System (PROMIS) Perspective on: Universally-Relevant vs. Disease-Attributed Scales. http://www.nihpromis.org/ Universally-Relevant_vs_Disease-Attributed_2014-2-12_final508. pdf. Accessed 11 March 2014. 